"Mircea cel Batran" Naval Academy Scientific Bulletin, Volume XIX - 2016 - Issue 1

Published by "Mircea cel Batran" Naval Academy Press, Constanta, Romania // The journal is indexed in:

PROQUEST / DOAJ / DRJI / JOURNAL INDEX / I2OR / SCIENCE LIBRARY INDEX / Google Scholar / Crossref /

Academic Keys / ROAD Open Access / OAJI / Academic Resources / Scientific Indexing Services / SCIPIO

\title{
ANALYSIS OF THE ACOUSTIC BEHAVIOR OF MULTILAYER PANELS WITH PERFORATED SHEET METAL FAÇADE ELEMENT AS COMPARED TO THE OUTSIDE NOISE
}

\author{
Alina - Elena CREȚU ${ }^{1}$ \\ ${ }^{1}$ Eng. Military Technical Academy 39- 49 George Cosbuc Bvd. Bucharest, Romania
}

\begin{abstract}
This project is a study about covering both structural and economical requirements in order to enhance the utility and pleasure of a perforated metal façade. Optimizes the use of the elements of the multilayer panels and are part of the facade of many buildings, based on the criterion of sound absorption of these multilayer boards which use perforated sheet mainly for esthetic reasons and thermal.
\end{abstract}

Keywords: acoustics, SoundFlow, absorption coefficient.

\section{BASIC CONCEPTS}

\subsection{The Sounds}

Sounds are vibrations mainly airborne, which can be perceived by the human ear and interpreted by the brain. They are characterized by its intensity, by the set of frequencies, and any variations thereof in time. People can interpret sounds as signals or noise, distinguishing the former as carriers of useful information, while the latter are undesirable sounds because they interfere with hearing the signal, its intensity or unpleasant frequency, or convey information not desired.

\subsection{Frequency}

Frequency is a measure of the number of repetitions of a periodic phenomenon per unit time. The International System unit is called hertz frequency and is symbolized by $\mathrm{Hz}$, the German physicist Heinrich Hertz in honor. A frequency of $1 \mathrm{~Hz}$ corresponds to a repetition period of one second. For example, we say of a woodpecker knocking beak into the bark of a tree 10 times per second, its head oscillates at a frequency of 10 $\mathrm{Hz}$.

The audible frequency range for people ranging from 20 to $20,000 \mathrm{~Hz}$. (Cycles per second), although in practice this varies from one person to another, again depending on the age of it. The sounds below $20 \mathrm{~Hz}$ are called infrasound and ultrasound $20.000 \mathrm{~Hz}$ above.

\subsection{Intensity}

Also called volume or amplitude of the sound. It is the quality that allows us to distinguish between loud and soft sounds. Strong as an ambulance siren and soft as a whisper. This intensity measures the sound pressure level (dB), which carries the sound wave on the particles of the medium through which it propagates.

\subsection{Decibels}

The intensity of the various noise is measured in decibels (dB), unit of measure of sound pressure. The threshold of hearing is $0 \mathrm{~dB}$ (minimum stimulus intensity) and the threshold of pain is 140 $\mathrm{dB}$.

To get an approximation of the perception of the human hearing, a unit based in $\mathrm{dB}$ is called decibel (dBA) was created. According to the OECD (Organisation for Economic Co-operation and Development), 130 million people face higher noise level at $65 \mathrm{~dB}$, the limit accepted by the World Health Organization (WHO), and another 300 million live in areas acoustic discomfort, ie between 55 and $65 \mathrm{~dB}$.

\subsection{Sound propagation}

Sound is transmitted through materials, solids, liquids or gases but not through empty media. To the sound may reach our ears need a space or propagation medium, this usually is usually the air.

In general the speed of sound is higher in the solid and lower in the gases. In gases the particles are further from each other and hence the frequency of interaction is lower than in liquids and solids. The speed of sound in air at $20^{\circ} \mathrm{C}$ is $345 \mathrm{~m} / \mathrm{s}$.

1.5.1 Physical phenomena affecting the propagation of sound

There are some phenomena that occur when the sound wave propagates, then discuss each one of them.

Absorption. It occurs when a sound wave reaches a surface; a portion of its energy is reflected, but a percentage of it is absorbed by the new medium.

Reflection. Occurs when a wave encounters an obstacle that can not pass and reflected (back to half of which comes).

Transmission. In many obstacles planes (walls of buildings) a portion of the energy is transmitted across the barrier. The amount of energy reflected, absorbed and transmitted is equal to the incident sound energy (original).

Dissemination. If the surface where the reflection occurs presents some roughness, the reflected 


\begin{abstract}
"Mircea cel Batran" Naval Academy Scientific Bulletin, Volume XIX - 2016 - Issue 1
Published by "Mircea cel Batran" Naval Academy Press, Constanta, Romania // The journal is indexed in: PROQUEST / DOAJ / DRJI / JOURNAL INDEX / I2OR / SCIENCE LIBRARY INDEX / Google Scholar / Crossref /

Academic Keys / ROAD Open Access / OAJI / Academic Resources / Scientific Indexing Services / SCIPIO
\end{abstract}

wave not only follows one direction but is decomposed into multiple waves.

Refraction. It is the deviation experienced by waves in the direction of propagation, when the sound passes from one medium to another different. Refraction is due to the change of environment, change the speed of sound propagation.

Diffraction. It is called the diffraction phenomenon that occurs when a sound wave are an obstacle to their smaller wavelength $(\lambda)$, it is able to surround him through it.

Another capability of the waves passing through holes changing its focusing spherical divergence in central diffraction éstosforma is.

\section{NOISE POLLUTION}

Managing urban noise centered on the control of noise generated by activities in the urban residential land, however, public sensitivity to this form of pollution is increased. So now the environmental management processes involved in management of environmental noise generated mainly railways, traffic, roads, airports, factories, ports, leisure on public roads, municipal services and works.

Environmental noise pollution due to excessive sound that disrupts normal ambient conditions in a given area. While noise does not accumulate, moved or maintained over time as other pollutants, can also cause extensive damage to the quality of life of people if not properly controlled, this, together with the degree of impact caused by a besides noise source depending on its intensity, also depends on the sensitivity to the noise that has the receiver.

Noise pollution is generated by unwanted sounds that negatively affect our quality of life thereby preventing the normal development of our activities.

\subsection{Major sources of noise pollution}

The main sources of noise pollution in our society come from motor vehicles (80\%); $10 \%$ corresponds to industries; $6 \%$ for rail and $4 \%$ in bars, public buildings, industrial workshops, aircraft, etc.

The current fleet of Spain, with more than 16 million vehicles, continuously generates a very loud noise, since only by rubbing tires with the road sounds Joined occur, resulting pollutants. The construction of motorways or bypasses several nearby population centers have increased the effect of road traffic and the sound it generates. There are areas particularly affected by being built near railway lines or airports. Without reaching these levels can be extreme, generally a multiple exposure outside the home environment, which affects the personal health of each individual suffers.

\subsection{External Noise Sources}

The external noise sources influencing the situation and arrangement of the volumes of the building at the stage of urban planning and the building envelope. Unfortunately those media that allow us to transport us from one place to another, such as cars, trains and planes originate high noise pollution, which today can even cause serious hardship to the people who have continuous exposure to these noises.

\subsubsection{Vehicles (Road Traffic)}

The noise emanating from road traffic has a random nature because it is composed of contributions of noise sources with different spectra and emission characteristics, such as heavy, light and passenger car vehicles, which also exist different noise producing parts. So the characterization of noise generated by the traffic requires a statistical treatment to obtain the same global index.

\subsubsection{Aircraft}

Of all the means of transport, airplanes are the ones that cause as much acoustic energy, which together with its dependence airports, causing great inconvenience to the towns next to them.

It can be said that the maximum noise levels occur at takeoff, due to high power engines, then next in importance overflight, and finally the landing, which is the operation in which the noise level generated is lower (20 decibels less than the normal flight).

Regarding noise emitted propeller aircraft, (frequently intended for passenger transport) produce predominantly low noise frequencies. To value these noises are special rates as necessary to take into account not only the specific noise spectrum and noise level, but also the number of flights that take place during the day and / or night.

\subsubsection{Trains}

The noise caused by rail traffic, noise is discontinuous in time, because it obeys discrete phenomena with a certain frequency step. This discontinuous nature makes it less annoying than road traffic noise, which is noise fluctuating nature.

The Underground Railroad does not increase the ambient noise, but due to the transmission of vibrations through the ground and through the structures, the Underground Railroad can cause considerable noise and vibration in buildings near the tunnels, being able to create danger to properties of such structures.

\section{ISOLATION AND ACOUSTIC ABSORPTION}

3.1 Difference between insulation and sound absorption 


\begin{abstract}
"Mircea cel Batran" Naval Academy Scientific Bulletin, Volume XIX - 2016 - Issue 1
Published by "Mircea cel Batran" Naval Academy Press, Constanta, Romania /I The journal is indexed in: PROQUEST / DOAJ / DRJI / JOURNAL INDEX / I2OR / SCIENCE LIBRARY INDEX / Google Scholar / Crossref /

Academic Keys / ROAD Open Access / OAJI / Academic Resources / Scientific Indexing Services / SCIPIO
\end{abstract}

These two concepts are used interchangeably when they should not be. So in the following lines will seek to address the differences between them.

Isolate is to implement measures aimed at decreasing the energy transmitted between one space and another, whereas with the use of absorbent materials is being made to act on the part of the reflected sound, and thus adapt the acoustic characteristics of the premises to its future use.

In this regard, it is essential to remember that absorption and isolation are opposites (when it is porous materials), although commonly in buildings is performing a job set both in order to supplement their potential.

\subsection{Sound absorption coefficient}

To evaluate the properties of a material absorbing the sound absorption coefficient $(\alpha)$, which is defined as the ratio between the energy absorbed by the material and the sound energy incident on it, which is based on the use frequency.

According to the HR DB, the values of sound absorption coefficient is specified and used in the calculations with a tenth round to the second figure.

Given this formulation its value is always between 0 and 1 The maximum absorption coefficient is determined by a value of 1 where all the energy incident on the material is absorbed by it, and the minimum is 0 where all the energy is reflected.

The absorption coefficient varies with frequency and therefore the manufacturer of acoustic materials give the absorption coefficients at least an octave resolution.

Typical construction materials have low $\alpha$ values and absorbent porous materials with elevated $\alpha$.

3.3 Factors affecting the sound absorption

Usually when we speak of interior partitions in buildings, the values of sound absorption coefficient also vary depending on the frequency of the incident sound, depend on:

a) The thickness of the absorbent material

b) The separation of the absorbent material relative to the partition or work element.

c) The density of the material.

a) The thickness of the absorbent material Porous materials have increased absorption at higher frequencies, as the thickness of the absorbing material is able to increase the absorption for all frequencies, but above all to increase the absorption in the low frequency range.

The thickness of the absorbent material is important since depending on this, the path of the sound wave within the material will be longer, thereby increasing the opportunities of friction on its path, which causes an increase of the energy transformed into heat in the internal pore structure. The graph below shows the behavior of glass wool at the increase in thickness.

\section{b) Separation of the absorbent material} compared to the rigid wall

This parameter is important because the absorbent material behavior depends not only on their characteristics but also on how it is implemented on site.

This is the principle known as acoustic ceilings are based on where porous materials are placed at a distance behind the slab and perforated panels.

\section{c) The density of the material}

This property is selected solely according to the strength properties of the material. The density is directly proportional to the absorption, the greater the density of the porous material will be greater sound absorption and lower absorption have lower density, due to frictional losses decrease.

\section{ANALYSIS AND RESULTS OF THE STUDY MODELS}

\subsection{Input data}

All models use a $1.5 \mathrm{~mm}$ thick plate with holes staggered and placed with airflow resistivity of 5 Kpa.s/m2.

In the model which has absorbent material is used in all cases Rockwool wool with properties of density and air flow resistance is $75 \mathrm{~kg} / \mathrm{m} 3$ to $45 \mathrm{kPa}$.s / $\mathrm{m} 2$ respectively.

Then discuss the absorption coefficient in each of the models and the changes produced by varying parameters such as the separation distance of the plate from the wall of the facade (d), the diameter of the holes $(\varnothing)$ and the porosity of the sheet $(p)$. For the analysis we reference the model with separation $\mathrm{d}=700 \mathrm{~mm}$, holes diameter $\varnothing=3 \mathrm{~mm}$ and porosity $p=40 \%$.

\subsection{Brief explanation of the software SoundFlow}

There are three versions of SoundFlow AFMG, which are used under license and are:. Basic, Standard and Pro Each of these versions have característicasdiferentes in their functionality and scope in the calculation. At this SoundFlow, as most programs have a trial version available short.

SoundFlow a simulation software for the calculation of absorption, reflection and transmission of sound in multilayer structures. Allows the modeling of wall structures, floor and ceiling by specifying layer materials and thickness. In the database these materials are divided into three classes: absorbent, perforated sheets and plates. The classification depends on the mechanisms of sound absorption and for each of the types, different physical properties are used to define it. 
"Mircea cel Batran" Naval Academy Scientific Bulletin, Volume XIX - 2016 - Issue 1

Published by "Mircea cel Batran" Naval Academy Press, Constanta, Romania // The journal is indexed in: PROQUEST / DOAJ / DRJI / JOURNAL INDEX / I2OR / SCIENCE LIBRARY INDEX / Google Scholar / Crossref /

Academic Keys I ROAD Open Access / OAJI / Academic Resources / Scientific Indexing Services / SCIPIO

The program can display the following calculation results:

4. Coefficient

5. absorbtion

Coefficient

reflection

6. transmission including input impedance real part and imaginary,and the magnitude and phase.

7.

Reflection

factor including real and imaginary part and the magnitude and phase.

In addition, the axes of the graphs shown, as well as the resolution of the frequency are adjustable. You can also define the direction of incidence, either by introducing a particular angle, considering normal incidence (our case) or assuming a diffuse field. The software interface is very intuitive and is divided into 4 sections:

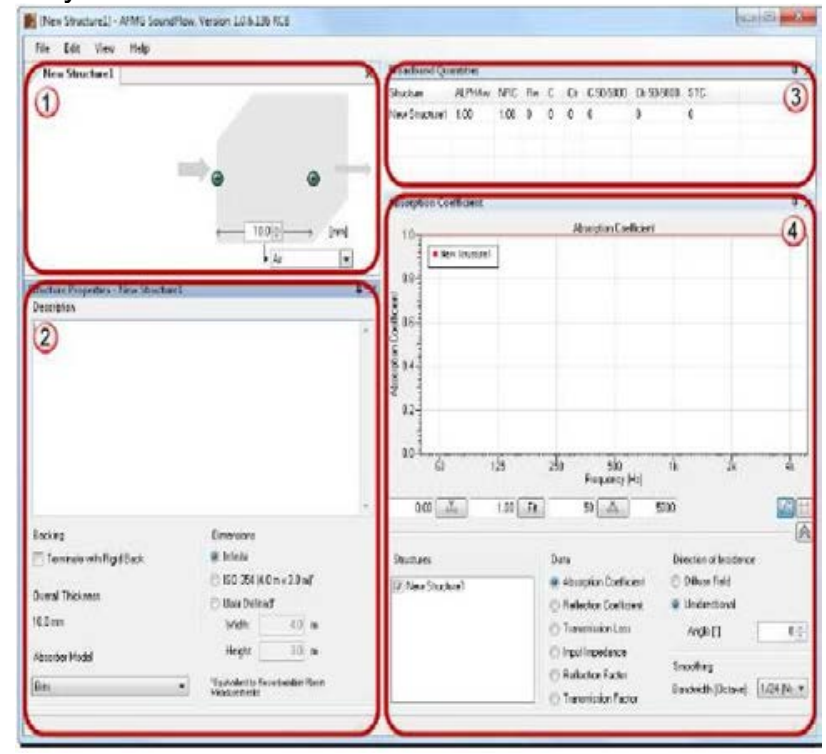

Fig. 1. AFMG program window SoundFlow

Section 1: Definition of the structure:

The pictorial representation of the structure to define the number of layers thickness and material.

Section 2: Properties of the structure:

The content of this window depends on the layer is selected in the structure. When a specific layer is selected edges will turn yellow and in this window properties that may be edited are displayed.

Section 3: Quantities broadband:
The table shows the set of indicators common broadband.

Section 4: Results Window:

The results can be displayed via a chart or by tables. When changes are made to the properties window the results are updated automatically.

4.2.1 Analysis of model 1: Sheet $(1.5 \mathrm{~mm})+$ Air + Wall

1. VARIABLE AND SEPARATION WALL PLATE [500 mm, $700 \mathrm{~mm}, 800 \mathrm{~mm}, 1000 \mathrm{~mm}$ ]
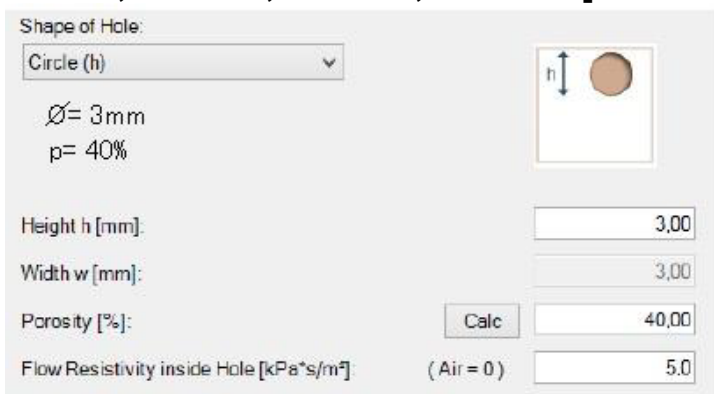

Fig. 2. Fixed variables 1 A. $d=500 \mathrm{~mm}$ :

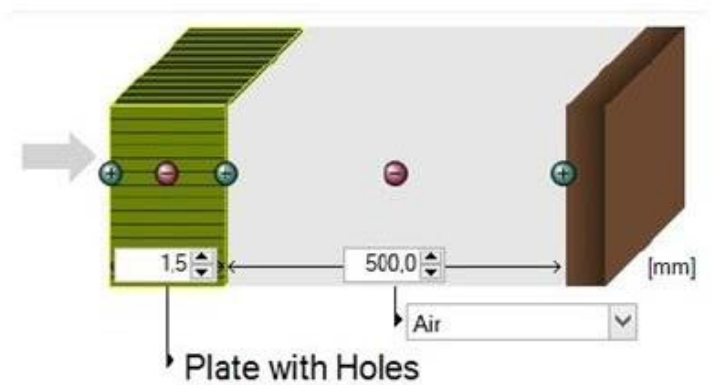

Fig. 3. Results $d=500 \mathrm{~mm}$. Model 1

\begin{tabular}{|l|l|}
\hline Absorption Coefficient \\
\hline Frequency $[\mathrm{Hz}]$ & New Structure ${ }^{-}$ \\
50 & 0.035 \\
63 & 0.053 \\
80 & 0.078 \\
100 & 0.110 \\
125 & 0.143 \\
160 & 0.166 \\
200 & 0.157 \\
250 & 0.097 \\
315 & 0.018 \\
400 & 0.051 \\
500 & 0.161 \\
630 & 0.057 \\
800 & 0.120 \\
1000 & 0.066 \\
1250 & 0.109 \\
1600 & 0.105 \\
2000 & 0.126 \\
2500 & 0.105 \\
3150 & 0.127 \\
4000 & 0.131 \\
5000 & 0.137 \\
\hline
\end{tabular}

Tabel 1. Results $d=500 \mathrm{~mm}$. Model 1 
"Mircea cel Batran" Naval Academy Scientific Bulletin, Volume XIX - 2016 - Issue 1

Published by "Mircea cel Batran" Naval Academy Press, Constanta, Romania // The journal is indexed in: PROQUEST / DOAJ / DRJI / JOURNAL INDEX / I2OR / SCIENCE LIBRARY INDEX / Google Scholar / Crossref /

Academic Keys / ROAD Open Access / OAJI / Academic Resources / Scientific Indexing Services / SCIPIO

ANALYSIS:

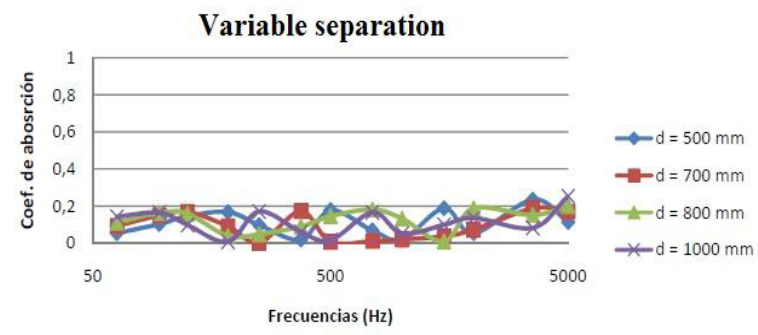

Graph 1. Analysis influence the separation of the wall plate. Model 1

No trend line fits properly.

By going by increasing distance from the wall plate to the curve relating the absorption coefficient with frequency is shifted to the left. For example, going from a separation of $500 \mathrm{~mm}$ to $700 \mathrm{~mm}$ the curve moves about $60 \mathrm{~Hz}$ while going from $700 \mathrm{~mm}$ to $800 \mathrm{~mm}$ about $15 \mathrm{~Hz}$. Moreover if we increase the separation other $200 \mathrm{~mm}$ only moves about $20 \mathrm{~Hz}$ so one sees that this shift is becoming increasingly smaller.

Therefore the choice of the most suitable separation depends on the frequency at which you want to reduce noise.

2. VARIABLE DIAMETER HOLE $[1 \mathrm{~mm}, 3 \mathrm{~mm}, 5$ $\mathrm{mm}, 10 \mathrm{~mm}$ ]

ANALYSIS:

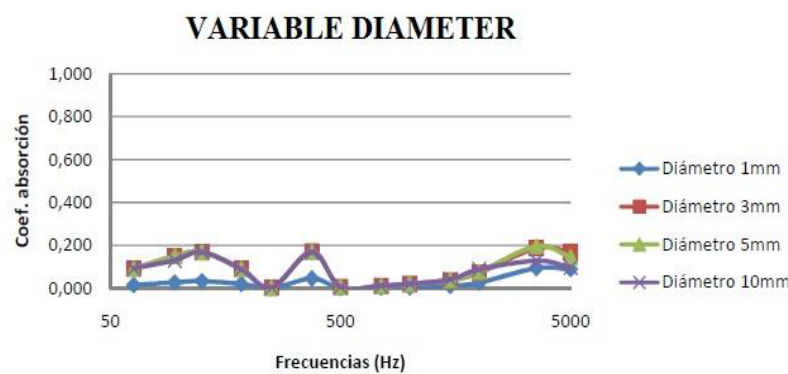

Graph 2. Analysis influence the diameter of the plate hole.Model 1.

No trend line fits properly. The same variation for different frequencies is produced. The variation is not uniform as the diameters increase.

The variation is not uniform as the diameters increase. For diameters of $3 \mathrm{~mm}, 5 \mathrm{~mm}$ and $10 \mathrm{~mm}$ the absorption coefficient varies. Similarly low frequency to approximately $1500 \mathrm{~Hz}$. For higher frequencies on all models occurs a lot noise which is not well represented in the graph, the only use 13 frequency values for analysis. It is practically impossible determine that sheet will behave better because they are generally wrong behavior 3 . Since a diameter of $1 \mathrm{~mm}$ and below reduces the coefficient absorption at all frequencies.

The biggest difference is in using perforated plates with holes of $1 \mathrm{~mm}$ in that for low frequencies the absorption coefficient is less than
$80 \%$ obtained using the other models. As frequencies increase this difference is reduced to be approximately $50 \%$ for the higher frequencies.

3. Varying porosity $[35 \%, 40 \%, 45 \%, 50 \%]$ ANALYSIS:

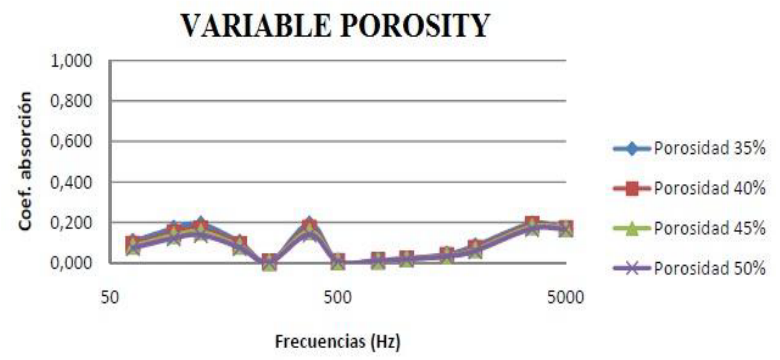

Graph 3. Analysis influence of the porosity of the sheet

No trend line fits properly.

The variation of the absorption coefficient for different frequencies is maintained more or less constant. Taking the $40 \%$ porosity model shows that at low frequencies the absorption coefficient obtained for plates with porosity $35 \%$ Is $10 \%$ higher and those obtained for plates with 45\% porosity and $50 \%$ are $10 \%$ and $15 \%$ lower, respectively. For "average" frequencies 500,1500 $\mathrm{Hz}$ the absorption coefficient is practically the same for all sheets and to "high" frequencies from $1500 \mathrm{~Hz}$ thing happens same as for the low percentages of minor variation.

Conclusions:

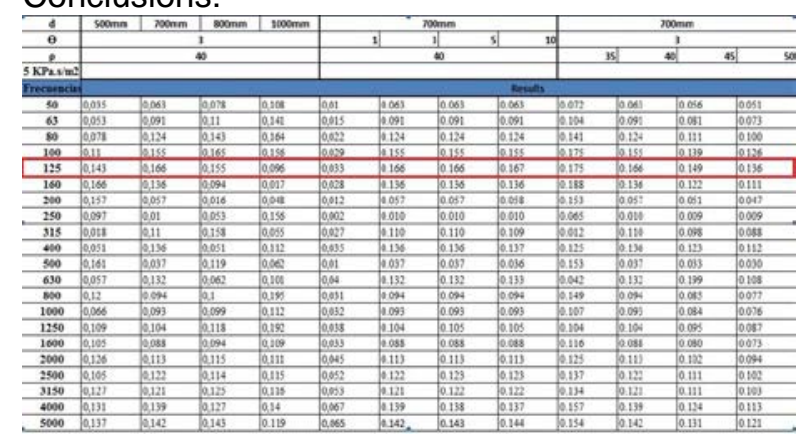

Tabel 2. Conclusions. Model I.

Focusing on the wing often we are interested in increasing the absorbtion acoustics to reduce traffic noise $125 \mathrm{~Hz}$,it is concluded that the best separation of the plate to the wall is $700 \mathrm{~mm}$.

Furthermore we are indifferent work with hole diameters of 3,5 or 10 so we kept the plates with holes of $3 \mathrm{~mm}$ diameter.Finally clearly shows that the lower the porosity will be greater absorbtion so in our case we will select the sheet with a percentage of open area of $35 \%$. 
"Mircea cel Batran" Naval Academy Scientific Bulletin, Volume XIX - 2016 - Issue 1

Published by "Mircea cel Batran" Naval Academy Press, Constanta, Romania /I The journal is indexed in: PROQUEST / DOAJ / DRJI / JOURNAL INDEX / I2OR / SCIENCE LIBRARY INDEX / Google Scholar / Crossref I Academic Keys / ROAD Open Access / OAJI / Academic Resources / Scientific Indexing Services / SCIPIO

\section{BIBLIOGRAPHY}

[1] TFG Rocio Olaguibel „Fachada de chapa perforada: análisis de su comportamiento acústico”

[2] Manual del Ruido, Departamento de Construcción arquitectónica, Ayuntamiento de las Palmas de Gran Canaria, 2006.

[3] Jornada Criterios Acústicos en el Diseño de Centros Docentes, Comportamiento acústico de los materiales y edificios, Centro Tecnológico Labein, Vitoria, Mayo del 2001.

[4] Espectro Audible, Julio 2013, [Online], Disponible en: http://es.wikipedia.org/wiki/Espectro_audible . 